\title{
Risk Assessment and Consequence Evaluation of Loss of Containment in Petroleum Industry
}

\author{
Chinwuko Emmanuel Chuka', Ifowodo Henry Freedom², Umeozokwere Anthony O. ${ }^{3}$ \\ ${ }^{1,2}$ Department of Industrial/Production Engineering, Nnamdi Azikiwe University, Awka, Anambra \\ State, Nigeria \\ Ifowodo_henry@yahoo.com (Ifowodo, H. F.), chinwukoemmanuels@yahoo.com (Chinwuko, E. C.)
}

\begin{abstract}
Major cases of process incidents are often traced to Loss of containment of crude oil. Loss of containment of crude oil plays an important adverse role not only because it waste lands, destroys vegetation/environment, cause a disaster in the ecosystem, renders sources of water supply unfit for drinking for local occupants but also because when come in contact with fire source it potentially leads to fire accident/explosion with severity ranging from minor damages to fatalities. The Petroleum Industry Safety Acts hold the achievement of prevention of losses of containment as an all important primary aim/objective. A mathematical modeling is therefore essential in risk assessment and consequence evaluation. This paper presents a quantitative loss of containment model for risk assessment and consequence evaluation by hazard classification and ranking to enable possibility of prevention or mitigation of losses of containments and ascertain the extent of damage done.
\end{abstract}

Keywords: Assessment, Classification, Consequence, Containment, Evaluation, Modeling, Rank, Risk

\section{BACKGROUND OF THE STUDY}

Loss of containment is a major problem facing the petroleum industry because not only that it dent the image and reputation of the industry but also because it may result to environmental pollution, destruction of the ecosystem on land and in the water bodies, wastage of land, vegetation destruction, loss of life and property; direct costs of products and lie downtime; environmental cleanup costs; possible fine and legal suits. The chief cause of loss of containment is traced to crude oil pipeline leak due to rupture, obsolescence, rust/corrosion, deliberate acts of vandalism and third party interference. Other causes may include mechanical integrity failures, poor process design or design fault [32], incomplete process technology documentation, inadequate hazard analysis, lack of management of change, unexpected or uncontrolled reactions, human error, etc [14].

Review of process data from loss of containment incidents reveals that in many cases the loss of containment was detectable for a significant length of time before plant staff became aware of the failure. If operators are alerted to a loss of containment in the early stages of a failure, they can often mitigate the consequences of the event. Real time comparison of process data to simple process models can detect some loss of containment incidents while they are in there early stages. For instance overflow of petroleum storage tank, leak in a surge vessel, leak from surface pipeline etc; in these incidents, early detection of the loss of containment would have allowed operators to take actions to prevent or significantly reduce the eventual consequences of the event [33].

Preventing loss of containment is a primary goal of the industrial Process Safety Management programs [13]. A thorough understanding of the hazards, identification of a complete range of failure events, detailed analysis of the consequences of failure events, and the analysis of process risks accounting for all the safeguards can help significantly in preventing and mitigating loss of containment incidents [13]. A fundamental understanding and detailed evaluation of the hazards is an important first step [6]. This may be much more involved than just reviewing or communicating material safety data sheets [6]. Next a complete range of failure scenarios should be analyzed in a systematic manner, including qualitative and quantitative methods, to develop information on potential consequences [6]. With an understanding of hazards and consequences and ideally some good process data, a process hazards analysis team, using a semi-quantitative risk analysis, can evaluate the adequacy of systems and the layers of protection necessary for preventing loss of containment events [6]. 
Process safety and risk management systems are implemented to reduce injuries and process incidents [8]. The effectiveness of these systems is dependent on the company's implementation and support for Operational Discipline (OD)-related programs to ensure that the Process Safety Management (PSM) system requirements are rigorously followed day-to-day at all levels of the organization [8]. However, OD-program-related problems continue to contribute to process incidents of Loss of Containment (LOC), especially since they may not be formally addressed during incident investigations [8].

\subsection{Statement of the Problem}

Loss of containment resulting from oil spills and other causes has been a major problem in Nigeria. The Niger Delta in particular is afflicted with massive oil spills. During October, 1998, an explosion and leak flooded a large part of the village of Jesse, killing more than 700 people; two years later, two pipeline explosions in southern Nigeria killed 300 people [40][3]. Large oil spills have turned large areas of the Ogonis' homeland into wastelands. In mid-2001, for example, a United Nations Internet page described Yaata, an Ogoni village [3], where "dying vegetation in various shades of ochre stretch as far as the eye can see, poisoned by soil turned soggy and a dark, greasy hue since crude oil began seeping through over a month ago." On April 29, at the Royal/Dutch Shell Yorla oil field [3], a "quake-like tremor sent shockwaves onto Yaata and surrounding villages." [41]. Within minutes, before people could guess the cause, jets of crude oil were already shooting up 100 meters, raining on the surroundings. The oil plume was quickly followed by strong fumes of natural gas, as the people of the village ran for their lives [3]. The rapidly resulting streams of crude oil swamped neighboring farmlands, forests, streams and rivers [25]. People in the areas pervaded by the fumes complained of breathing difficulties, in a number of cases combined with cough and runny noses [3]. The village became uninhabitable [3]. Their maize, cassava and yam crops were stained with crude oil, wilted and dying. Much of their livestock had either died or was dying from eating polluted vegetation and drinking contaminated water. Dead fish rose to the surface of creeks and ponds [41][3]. In the meantime, the spilled oil seeped further into the earth, contaminating underground water for miles around [3]. In yet another occasion, People living in the community of Ogbodo, on the banks of the Miniamu River, were engulfed with irritating odor and itching every morning [3] and could no longer drink from the river which is their major source of water supply due to oil spill. All these are to mention but a few of problems resulting from loss of containment in the petroleum industry in Nigeria generally and in Niger Delta Particularly. Hence it is imperative to prevent loss of containment in the petroleum industry and therefore risk assessment and consequence evaluation is inevitable.

\subsection{Objectives of the Study}

The objectives of the study were:

- To identify and recognize hazards associated with loss of containment.

- To model and simulate a model for risk assessment and consequence evaluation of loss of containment.

- To carryout risk assessment of loss of containment and evaluate their consequences by classification and ranking.

\section{LITERATURE REVIEW}

In the recent past, the quantity of crude-oil extracted and transferred between points of production, processing and distribution or export terminals has greatly increased as the demand of and dependence on oil increased. Although this increase in production level contributes to the national economic growth it also presents increase in potential for environmental pollution and degradation resulting from loss of containment. Experience has shown that oil spills in the environment holds negative consequences. Apart from the problem of air pollution and vegetation loss, there is reduction in the use of aquatic resources and soil degradation. Intricate and widespread pipeline network are all over the Niger Delta region, which is the hub of Nigeria's crude-oil extraction and production. It has been observed that thousands of barrels have been spilled into the environment through loss of containment from oil pipeline leaks and storage facilities overflow or failures in Nigeria.

The major cause of loss of containment is pipeline damage and leakage which can differ ranging from material defects and pipe corrosion to ground erosion, tectonic movements on the sea bottom and contact with ship anchors and bottom trawls [15] particularly in the offshore operations while 
vandalism is observed as the substantial cause of loss of containment resulting from pipeline damage onshore in Nigeria [39].

In a related effort to effectively manage loss of containment in Nigeria, a co-operative of oil industry operators known as Clean Nigeria Associate (CNA) was formed in 1981 [7], which amongst others, maintains the required capability for loss of containment emergency response within the 1st and 2nd Tier spill response system of its members [39].

Nigeria as a signatory to the international convention on Oil Pollution, Preparedness and Response Co-operation [26] that focuses on the responsibility of member states to establish a national system or plan for responding effectively to oil pollution incidents, developed a National Oil Spill Contingency Plan (NOSCP) [21], which was revised in 2003 and reviewed in 2006 [29]. The Government established the National Oil Spill Detection and Response Agency (NOSDRA) in 2006 as part of its effort in implementing the NOSCP [39].

The National Oil Spill Detection and Response Agency (NOSDRA) [31] is charged with the responsibility of implementing the National Oil Spill Contingency Plan (NOSCP) for Nigeria in line with the international convention on Oil Pollution, Preparedness and Response Co-operation, which Nigeria is a signatory [18]. The agency is also empowered to timely, effective and appropriate response in terms of necessary equipment and resources to protect threatened environment and facilitate clean up of affected sites to the best practical extent [20] including remediation and restoration [39].

The primary roles of the Agency among others include:

- Maintain surveillance and ensures compliance with all existing environmental legislation as well as the detection of loss of containment/oil spills in the petroleum sector [16];

- Receives reports of all oil spillages and co-ordinate oil spill response activities throughout Nigeria [16];

- Co-ordinates the implementation of the plan for removal of hazardous substances as shall be directed by the federal government [16];

- The Agency has the responsibility to strengthen the national capacity and regional action to prevent, control, combat and mitigate marine pollution [20].

It is therefore regrettable that despite all these efforts and strategies put in place by the Nigerian Government and Oil Industry Operator oil spill/loss of containment incidences still occur unabated [39].

In Nigeria, oil spill/loss of containment did not receive attention until late 1970's, when formal documentation commenced. From available statistics, a total of 9,107 losses of containment incidences occurred between 1976 and 2005 resulting in about 3,121,909.8 barrels of oil loss of containment spilled into the environment [17]. Some of the major oil spills/ losses of containments recorded in Nigeria include:

- The Escravos loss of containment of about 300,000 barrels in 1978;

- The oil blowout of 1980. In the spillage which involves Texaco Oil Company, over 400,000 barrels of oil loss of containment spread through the Niger Delta region polluting about $1,200 \mathrm{~km}^{2}$ [7]. In the disaster about 180 people died while 300 people contacted various illnesses through drinking of polluted water and eating contaminated food [42][7].

- Another recounted incidence of loss of containment occurred in 1986. It was estimated that major creeks and villages were affected by the spillage [7]. In this loss of containment incident, several thousand of barrels of oil were lost and economic activities were paralyzed in the affected regions. The damage done to fishponds, nets and traps was put over 2 million Naira [42][7].

- Mobile loss of containment of crude oil of 1998 polluted waters from Akwa Ibom State in the South to Lagos State in the West. It was observed that the loss of containment was over 40,000 barrels of oil to the environment [7].

- The Jesse loss of containment incident of 1998, which resulted in a fire that claimed over a thousand lives and ravaged the fragile ecosystem [24] [39]. 


\subsection{Risk}

The "risk" is the product of consequence and likelihood of each scenario [1] of an unwanted event. The risk for each scenario can be combined by specific areas or for the whole facility to obtain desired risk profiles. The risk is calculated using event and fault trees that take into account safety and mitigation systems [12] [31].

\subsubsection{Risk Tolerance}

After the risk is calculated, the results must be compared to either governmental or company criteria to determine if the risk is tolerable [1]. This means that the risk is at a level people are generally willing to accept [1]. If the level of risk does not meet the "acceptable" risk criteria, then additional mitigation may be required [1]. The options for reducing the risk are selected and the analysis recalculated to determine the impact on the risk [1]. In some cases, the options provide significant risk reduction, whereas others have little impact on the risk [1]. One concept that is being used extensively is as low as reasonable practical (ALARP) [1]. This concept suggests that, at some point, the cost to mitigate a hazard is so high that it is no longer practical to implement the option. Cost-benefit analysis can be used to determine if ALARP has been achieved [1] [31].

\subsubsection{The Use of Risk Assessment}

Risk assessment is a process where the results of a risk analysis are used to make decisions, either through a risk ranking of hazard reduction strategies or through comparison to target risk levels and cost-benefit analysis [1]. Risk assessment techniques can be used to determine [1] the loss of containment prevention required methods for a given hazard by conducting an analysis or calculations to define the [1] loss of containment prevention required to mitigate the hazards. The process consists of a series of steps [10]. Each step in the risk assessment process is discussed in the following sections [1] [31].

\subsubsection{Hazards Analysis}

The first step in any risk assessment is to conduct a hazard analysis [10]. The hazard analysis techniques used to identify potential hazards in the process [10] and facility. Typical facilities where hazard analyses are performed include refineries, storage terminals, gas plants, platforms, floating production/storage and off loading floating storage etc, or any combination of these [10]. However, this approach can be used for Liquefied Natural Gas facilities, gas turbine generator stations, power plants or practically any type of energy-production facility [10].

The outcome of a hazard analysis is a list of potential hazards [10] that may result from loss of containment. A partial list could include jet fire, pool fire, explosion [1], vegetation loss, loss of lives and property etc. The list would also include the corresponding location where each could occur [12]. These hazards can then be turned into scenarios for further analysis. A common mistake is to list just the hazards, where as a scenario is a series of events that need to occur to create a hazard [12] [31].

\subsubsection{Consequence Analysis}

Consequence analysis is the process used to determine the impact or magnitude of the scenarios [1]. In assessing the consequences, there are two very important questions that must be addressed [1]:

- What is the range in size of the events that can occur?

- What is the impact of the event?

In performing any consequence analysis, analytical tools can be very useful in determining the consequences of a scenario. In most cases, each scenario will have a variety of conditions that need to be evaluated in the consequence analysis [1]. This includes factors such as the size of the release, orientation of the release, temperature and pressure of the operation, and weather conditions (that will all vary) [1]. The impact of these variables on the results and the behavior of the release must be taken into consideration during the modeling [1].

A question that often arises during the consequence analysis is how sophisticated the program needs to be [1]. Programs range from spreadsheets that use simple equations to computational fluid dynamics (CFD) modeling that can take days for a single scenario evaluation [1]. The answer is that it depends on the complexity of the design, the time the analysis is being performed and the desired 
results [1]. In the conceptual stage, simple models can be used, but as the design details increase, the complexity of the consequence analysis frequently also increases [1] [31].

\subsubsection{The Bow-Tie Concept}

The Bow-Tie concept is a method used for controlling risks/hazards. The method for building a bowtie involves asking a structured set of questions in a logical sequence [9]. The completed Bow-Tie illustrates the hazard, the undesirable event, the safety events and potential outcomes, and the hazard controls put in place to minimize the risk [9].

The method involves placing barriers to prevent certain undesirable events from happening [9]. A control can be any measure taken that acts against some undesirable force or intention, in order to maintain a desired state [9]. In the Bow-Tie concept there are preventive barriers (on the left side of the Undesirable Event) that prevent the Undesirable Event from happening [9]. There are also corrective or reactive controls (on the right side of the Undesirable Event) that prevent the Undesirable Event from escalating or resulting into unwanted Outcomes or mitigating the consequence severity of the Outcomes [9] as shown in fig. 1 below.

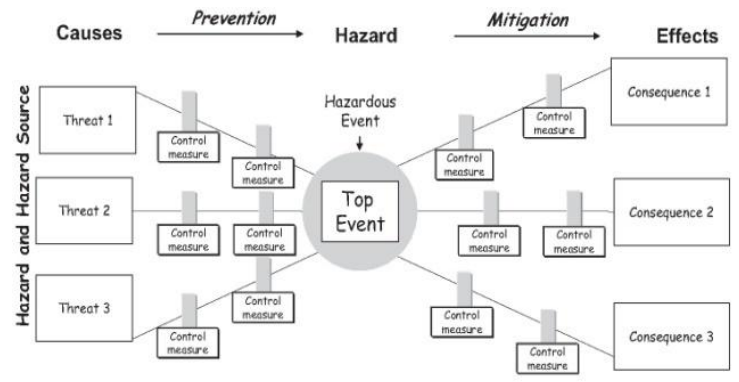

Fig1. Bowtie Measures to control threats (Prevention) and measures to control escalation (mitigation) [35].

\subsubsection{Risk Assessment Matrix (RAM)}

The Risk Assessment Matrix (RAM) is a tool to rank, assess risks and discuss what changes need to be made so that the risk is as low as is reasonably practicable (ALARP) [11] [31].

Assessing the risk of a particular scenario should be done in sequence, i.e. first the potential consequences are estimated and only thereafter the likelihood of such consequences occurring is assigned [11]. (A scale of consequences from 1 to 5 is used to indicate increasing severity) [11]. After assessing the consequences, the likelihood on the horizontal axis is estimated on the basis of historical evidence or experience that such consequences occurred [11].

Risks should be reduced to the lowest reasonably practicable level by taking preventative measures, in order of priority. This is what is meant by a hierarchy of control [19].

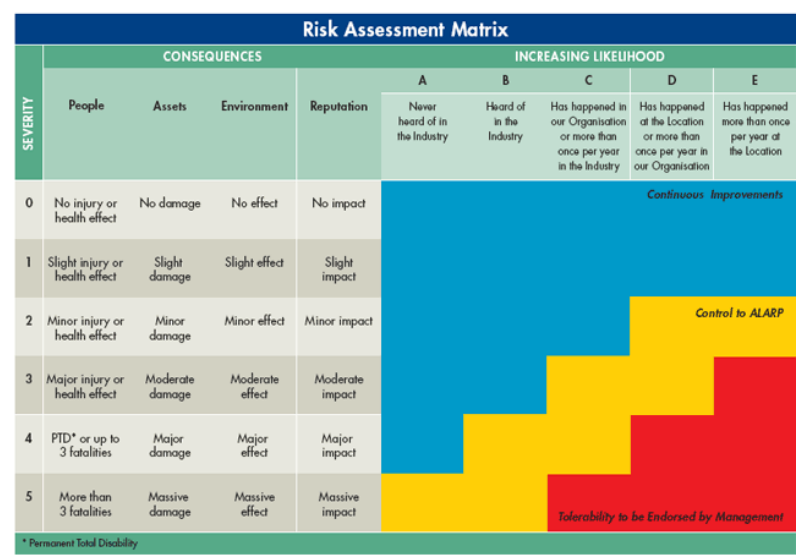

Fig2. A risk assessment matrix chart [43].

\subsection{Review of Past Work}

Loss of containment models that have been proposed in the last two decades by different authors varied both in the problem and mathematical formulations. Whereas some authors focus on the problem formulation without mathematical back-up, others focus on both but to different extent and 
dimension with parallel mathematical models. While most authors concentrate on either liquid- or gas- loss of containment models, some other built their models to accommodate both the liquid and gaseous phases of the loss of containment.

[34] have formulated a model on preventing loss of containment using the a fault tree analysis (FTA) with detailed job hazard analysis documentation on how to eliminate or minimize the causes of loss of containment such as substandard design process, mechanical integrity failure, insufficient job-hazard analysis, man-made error, poor implementation of change, unforeseen or sudden events, etc. But there are a number of uncertainties in the model and some variables are poorly known.

[28] have proposed a set of rules for guiding against loss of containment in which problems associated with loss of containment were discussed to some details. The causes and effects of loss of containment were properly x-rayed and this typical approach has worked very well reversing the fire incidents and accidents that were frequent and rampant in the Ricardo gas distribution company in Warri, Delta State. But their proposal has no mathematical model or back-up.

[35] have presented a Loss of containment model for energy in closed systems conduits and harmful (flammable and toxic) chemicals, in which they qualitatively and quantitatively analyzed an entire series of failure cases systematically, to create information on probable severities. The model describes a comprehensive risk, job hazards analysis and their severities with stages on prevention of loss of containments scenarios can be evaluated. However, some of the equations widely used are needed to be improved.

[33] have proposed a rational model for loss of containment detection and hazards reduction. They provided examples of loss of containment events that could have been detected by comparison of process data to simple process models. These incidents include: 1) Overflow of a petroleum storage tank in the 2005 Bunce field incident, 2) Leak in a hydrocracker pre-heater and 3) Leak of heat transfer fluid into a fixed bed catalyst reactor. In these incidents, early detection of the loss of containment would have allowed operators to take actions to prevent or significantly reduce the consequences of the event.

[30], in their on-the-job safety and hazards control systems documentation, have presented a loss of containment model to be put to practice to enable effective reduction of hazards and on-the-job accidents. The model depicts how ineffective consequence management increases on-the-job safety risks and hazards and can aid loss of containment (LOC) incidents, and presents an example of how to track and identify weaker consequence management characteristics, the consequence managementrelated problems, root causes etc using consequence management characteristic data obtained during incident investigations. The effectiveness of their model is dependent on its application and back-up from consequence management related programs in order that on-the-job Safety risks and hazards control system necessities are rigorously carried-out day-to-day at every stage in the industry. But consequence management program-related issues keep on aiding Loss of Containment (LOC) incidents, since they are not normally addressed during root cause analysis.

In this work, unlike most of the surveyed work, a stepwise logical and coherent model is presented to adequately assess the risks associated with loss of containment by identifying, recognizing, classifying and ranking of its hazards to enable its consequences evaluated for prevention, mitigation and apportioning appropriate compensation to the extent of damages done, should loss of containment occur after all measures put in place to avert it.

\section{MethodologY}

From the onset and foregoing, we have been able to identify and recognize the hazards associated with loss of containment. This section gives

- A detailed description of the modeling and simulation used for estimating the hazards effects for the risk assessment and the consequence evaluation of loss of containment of crude oil; a quantitative model adapted from Dow Chemical Exposure Index for a toxic and a flammable fluid [36].

- The classification of hazards consequences

- The ranking of the consequences. 


\subsection{The Model Formulation}

In outline, the model comprises the following stages:

1. Selection of scenario (pipe, hose, vessel; ruptures)

2a. Calculate emission (gas)

2b. Calculate emission (liquid)

3. Calculate mass released.

4. Calculate flash fraction.

5. Calculate airborne quantity due to flash.

6. Calculate pool size.

7. Calculate airborne quantity due to evaporation.

8. Calculate total airborne quantity.

9a. Calculate hazard distance and injury/fatality areas (toxic release)

9b. Calculate hazard distance and injury/fatality areas (flammable release)

10a.Calculate appropriate population density (toxic release).

10b.Calculate appropriate population density (flammable release).

11. Calculate number of injuries and fatalities.

12. Calculate hazard rank.

The stages of the model are given here in details.

\subsubsection{Select Scenario}

The purpose of scenario selection is to determine which process piping or equipment has the greatest potential for the release of significant quantity [2] of crude oil. E.g.

\section{Process Pipes}

Rupture of the largest diameter process pipe as follows:

- For smaller than $50 \mathrm{~mm}$ diameter - full bore rupture [2] i.e. $\quad D=d \quad d<50$

- For 50 to $100 \mathrm{~mm}$ diameter pipe - the rupture diameter is equal to $50 \mathrm{~mm}$ i.e $D=50$; $50 \leq d \leq$ $100[2]$

- For greater than $100 \mathrm{~mm}$ diameter - rupture area equal to $20 \%$ of pipe cross section area [2] i.e

$D=0.5 d \quad d>100$

\section{Hoses}

Full bore rupture [2].

\section{Pressure Relief Devices Relieving Directly to the Atmosphere}

Calculated total release rate at set pressure. Refer to pressure relief calculation or contact process engineering. All material released is assumed to be airborne [2].

\section{Vessels}

Rupture based on largest diameter process pipe attached to the vessel using pipe criteria above [2].

\section{Tank Overflows and Spills [2]}

\section{Others}

Scenarios can be established based on the plant's or technology's experience, they can be the outcome of a review or derived from hazard analysis studies. They can also be based on the experience of another technology if the event could occur in this unit [2]. Contact Process Engineering for special cases that may include reactivity or mixtures [2]. 
Releases from all scenarios are assumed to continue for at least five minute duration [2]. If a release is instantaneous or exceeds the total inventory within this duration, the release rate is calculated by dividing the total inventory by five minutes [2].

\subsubsection{Calculate Emissions}

Equations are given for mass flows of gas and of liquid. It is necessary, however, to take into account also the inventory and the period of release. The total mass released should not exceed the inventory. And there may be a time limit to the period of the release.

\subsection{2a Calculate Emission (gas)}

The following equations, based on the sonic gas flow rate equation, are used to estimate the airborne quantity (AQ) for a gas release [2].

$$
(A Q)=4.751(10)^{-6} D^{2} P_{a}\left(\frac{(M W)}{T+273}\right)^{1 / 2} \quad(\mathrm{Kg} / \mathrm{sec})
$$

\subsection{2b. Calculate Emission (liquid):}

$L=9.44(10)^{-7} D^{2} \rho\left(\frac{1000 P_{g}}{\rho}+9.8 \Delta h\right)^{1 / 2}(\mathrm{Kg} / \mathrm{sec})$

\subsubsection{Calculate mass of liquid released}

The total amount of material contributing to the pool formation must be estimated in order to determine the pool size [4]. If a release is large enough to empty a vessel in less than 15 minutes (including very large releases that occur in less than 5 minutes), the mass of liquid entering the pool is the total inventory of the vessel [4]. For a longer duration continuous release (one lasting more than 15 minutes) the pool is assumed to reach a final size after 15 minutes [4]. In this case, the mass determining the pool size is the release rate times 15 minutes (900 seconds) [4].

$W_{T}=t L \quad t=900$

The total liquid release $\left(W_{T}\right)$ is the tank inventory (the tank is emptied in less than 15 minutes) or given by [4]: $\quad W_{T}=900 L(\mathrm{Kg})$

Compare the calculated $W_{T}$ to the inventory of the system involved in the release [4]. The total liquid assumed to be involved in the release is taken as the smaller of these two values [4].

$W_{T}=$ smaller of calculated $W_{T}$ or system inventory

\subsubsection{Calculate flash fraction}

Compare the operating temperature of the liquid to its normal boiling point. If the temperature is less than the normal boiling point, the flash fraction is zero [2]. If the temperature is greater than the normal boiling point, calculate the fraction flashed (Fv). The fraction of the liquid that will flash (Fv) when released is given by [4]:

$F_{v}=\frac{C_{p}}{H_{v}}\left(T_{s}-T_{b}\right)$

If the needed information of a chemical cannot be found, then a value of 0.0044 (SI) may be used for the ratio $\mathrm{Cp} / \mathrm{Hv}$ [2]. If $20 \%$ of the material flashes, the entire stream becomes airborne and there is no pool formed [2].

\subsubsection{Calculate airborne quantity due to flash}

$\left(A Q_{f}\right)=5 F_{v} L(\mathrm{Kg} / \mathrm{sec})$

If $\mathrm{Fv} \geq 0.2$ then $A Q_{f}=\mathrm{L}$ and no pool is formed [2].

\subsubsection{Calculate pool size}

The total mass of liquid entering the pool $(\mathrm{Wp})$ is given by [2]: $\quad W_{p}=W_{T}\left(1-5 F_{v}\right)$

Please note that if none of the material flashes [4], 
$W_{p}=W_{T}(\mathrm{~kg})$

The pool area (Ap) is given by [2]:

$A_{p}=100 \frac{W_{p}}{\rho} \mathrm{m}^{2}$

\subsubsection{Calculate airborne quantity due to evaporation}

Airborne Quantity evaporated from the pool surface $\left(A Q_{p}\right)$ is given by [2]:

$\left(A Q_{p}\right)=9.0(10)^{-4}\left(A_{p}^{0.95}\right) \frac{(M W) P_{v}}{T_{p}+273} \mathrm{Kg} / \mathrm{sec}$

\section{Condition 1}

If the liquid is at or above ambient temperature but below its normal boiling point, the characteristic pool temperature is equal to the operating temperature [2]. i.e. $T_{p}=T \quad T_{a}<T<T_{b}$

\section{Condition 2}

If the liquid is at or above its normal boiling point, the characteristic pool temperature is the normal boiling point of the liquid. The normal boiling point is the boiling point of the liquid at atmospheric pressure [2]. $\quad T_{p}=T_{b} \quad T \geq T_{b}$

\subsubsection{Calculate total airborne quantity}

The total airborne quantity (AQ) is calculated by:

$$
(A Q)=\left(A Q_{f}\right)+\left(A Q_{p}\right) \quad\left[\left(A Q_{f}\right)+\left(A Q_{p}\right)\right]<L
$$

If the total Airborne Quantity (AQ) is greater than the liquid flow rate (L), set $\mathrm{AQ}=\mathrm{L}$ [2].

$$
A Q=L \quad\left[\left(A Q_{f}\right)+\left(A Q_{p}\right)\right] \geq L \quad \mathrm{Kg} / \mathrm{sec}
$$

\subsection{9a. Calculate hazard distances and injury/fatality areas (toxic release)}

The Hazard Distance (HD) is the distance to the ERPG-1, -2 or -3 concentrations and is derived from the following equation [2]:

$H D=6551\left(\frac{(A Q)}{E R P G-3}\right)^{1 / 2} \mathrm{~m}$

This is the basic Dow hazard distance.

Use is made of the EPRG-3 value. The EPRG-3 value is the concentration to which virtually all persons could be exposed for one hour without life-threatening effects [2].

What is required, however, is the concentration which has, say, $50 \%$ probability of fatality for 5-10 minutes exposure. It is necessary therefore to increase the concentration, both to allow for the shorter time of exposure and to adjust the toxic effect from injury to fatality. Use is made of a factor of 10 for time adjustment for concentration so that

$H D_{i}=\frac{H D}{10^{1 / 2}} \mathrm{~m}$

Likewise, in order to allow for the fact that a concentration which is fatal is higher than one which is no more than injurious, use is made of another factor of 10 for effect adjustment from injury to fatality so that: $\quad H D_{f}=\frac{H D_{i}}{10^{1 / 2}} \mathrm{~m}$

Then the area for toxic injury is: $A_{t i}=\frac{\pi}{4}\left(H D_{i}\right)^{2} \mathrm{~m}^{2}$

And toxic fatality is: $\quad A_{t f}=\frac{\pi}{4}\left(H D_{f}\right)^{2} \mathrm{~m}^{2}$

\subsection{9b. Calculate hazard distances and injury/fatality area (flammable release)}

For a flammable release the same equation is used for hazard distance, but with the lower flammability limit in place of the ERPG value. Burgoyne lists the LFLs of hydrocarbons from which a typical value is 
$C_{l f l}=0.05 o z f t^{-3}=0.05 g l^{-1}=50,000 \mathrm{mgm}^{-3}$

Hence; $\quad H D_{f l}=6551\left(\frac{(A Q)}{C_{l f l}}\right)^{1 / 2} \mathrm{~m}^{2}$

The effective diameter of the cloud is taken as half this value: $\quad D_{f l}=0.5 H D_{f l} \mathrm{~m}$

For flammable clouds only fatalities are calculated. For this it is assumed that all persons inside the ignited cloud are killed, but no others. Hence

$A_{f l f}=\frac{\pi}{4}\left(D_{f l}\right)^{2} \mathrm{~m}^{2}$

\subsubsection{0a. Calculate appropriate population density (toxic release)}

\section{Basic works population density}

For the basic works population density use is made of a value of $D_{p}=0.003$ persons $\mathrm{m}^{-2}$.

\section{Effect of escape/shelter}

It is not realistic to assume that if a hazardous release occurs, persons affected will remain in the path of the cloud. They will seek to escape. This is particularly so for the relatively small releases which are of principal concern here. In some cases they will escape into, or already be in, shelter. It is assumed that for toxic gas clouds the probability of no escape/shelter is $1 \mathrm{in} 30$. This effect will be taken into account by dividing the population density by 30 or in other words using an escape/shelter mitigation factor $E=0.033$. The effective population density after allowance for escape/shelter is: $D_{p e}=E D_{p}$

\subsubsection{0b. Calculate appropriate population density (flammable release)}

\section{Basic works population density}

The same population density is used as for the toxic release case, namely $D_{p}=0.003$ persons $\mathrm{m}^{-2}$.

\section{Effect of escape/shelter}

Again it is necessary to allow for escape/shelter. It is assumed that for toxic gas clouds the probability of no escape/shelter is 1 in 10 so that $\mathrm{E}=0.1$. This value is higher than that proposed for toxic release. One reason is that toxics tend to give more warning by odour. Another is that whereas a toxic cloud is always harmful, a flammable cloud is so only when ignited, which occurs only in a small proportion of cases. Thus people tend more often to try to stop it and so expose themselves. When ignition occurs, the flame tends to spread rapidly through the cloud. The effective population density after allowance for escape/shelter is: $\quad \mathrm{D}_{\mathrm{pe}}=\mathrm{ED}_{\mathrm{p}}$

\section{Effect of ignition}

With a flammable cloud there is a further factor, the probability of ignition. For a gas leak this probability increases with the size of the leak. A graph is given in Lees. The line can be fitted by the equation

$\mathrm{P}_{\mathrm{i}}=\exp [-4.16+0.642 \ln (\mathrm{AQ})] \quad \mathrm{P}_{\mathrm{i}} \leq 0.3$

This equation covers the range of emission rates up to $100 \mathrm{kgs}^{-1}$. Most emissions of interest here will be within this range. However, for present purposes extrapolation of the equation to higher flows is probably acceptable. The effective population density adjusted for cloud ignition is

$\mathrm{D}_{\text {pei }}=\mathrm{P}_{\mathrm{i}} \mathrm{D}_{\text {pe }}$

\subsubsection{1a. Calculate number of injuries and fatalities (toxic release)}

The number of injuries is then: $I=A_{t i} D_{p e}$

And fatalities: $F=A_{t f} D_{p e}$

\subsubsection{1b. Calculate number of injuries and fatalities (flammable release)}

Only fatalities are considered. The number of fatalities is: $\quad F=A_{f l f} D_{p e i}$ 


\subsection{Hazard Classification and Ranking Scheme}

Hazard classification and ranking scheme of [38] is given below:

\subsubsection{Catastrophic Consequences: Severity 5}

Catastrophic damage and severe clean-up costs

On-site: loss of normal occupancy $>3$ months

Off-site: loss of normal occupancy $>1$ month

Severe national pressure to shut down

Three or more fatalities of plant personnel

Fatality of member of public or at least five injuries

Damage to SSI or historic building

Severe environmental damage involving permanent or long-term damage to a significant area of land [5]

\subsubsection{Severe Consequences: Severity 4}

Severe damage and major clean-up

Major effect on business with loss of occupancy up to 3 months

Possible damage to public property

Single fatality or injuries to more than five plant personnel

A 1 in 10 chance of a public fatality, severe media reaction

Short-term environmental damage over a significant area of land [5]

\subsubsection{Major Consequences: Severity 3}

Major damage and minor clear-up

Minor effect on business but no loss of building occupancy

Injuries to less than five plant personnel and a 1 in 10 chance of fatality

Some hospitalization of public

Short-term environmental damage to water, land, flora or fauna

Considerable media reaction [5]

\subsubsection{Appreciable Consequences: Severity 2}

Appreciable damage to plant

No effect on business

Reportable near miss incident

Injury to plant personnel

Minor annoyance to public [5]

\subsubsection{Minor Consequences: Severity 1}

Near-miss incident with significant quantity released

Minor damage to plant

No effect on business

Possible injury to plant personnel

No effect on public, possible smell

\subsection{Calculate and Rank the Hazard}

The hazard rank is based on the system of [38] in particular on their relations between rank and number of injuries and fatalities in the works. These are: 


\section{Rank}

- Possible injury

- Injury

- Injuries up to 5, 0.1 probability of fatality

- Injuries to more than 5, single fatality

- Three or more fatalities

Based on this the following table has been constructed according to the severities.

\begin{tabular}{|c|c|c|}
\hline Rank & Injuries & Fatalities \\
\hline 1 & $I<0.1$ & $F<0.01$ \\
\hline 2 & $0.1 \leq I<0.5$ & $0.01 \leq F<0.05$ \\
\hline 3 & $0.5 \leq I \leq 5$ & $0.05 \leq F \leq 0.5$ \\
\hline 4 & & $0.5<F<3$ \\
\hline 5 & & $F \geq 3$ \\
\hline
\end{tabular}

[32]. the basis of this table is as follows. The injury range values for Ranks 1-3 are an approximate encoding of the severity categories of [38]. The fatality range values for Ranks 1-3 are one tenth of the injury values and those for Ranks 4-5 are an approximate encoding of these authors' categories. It is intended that the rank be determined both using injuries and using fatalities, where both have been calculated, and that if there is a difference of rank, the higher be used.

\subsection{Data Collection}

The parameters needed for the simulation of the particular scenario given below were obtained from the field based library office of the Nigerian Petroleum Development Company Limited (NPDC), Olomoro oil field.

\section{Extract}

In an emergency facility shutdown due to community interface relation issues, crude oil was temporarily and unintentionally accumulated in a horizontal low pressure (LP) separator whose diameter is $20 \mathrm{inch}$ and length $60 \mathrm{inch}$ at normal vapour pressure and surrounding temperature of $30^{\circ} \mathrm{C}$. After three days, the 2 inch outlet line of the LP separator has broken. The required information of the LP separator is:

\begin{tabular}{|c|c|}
\hline Operating pressure & $344.5 \mathrm{Kpa}$ \\
\hline Operating Temperature & $32.2^{\circ} \mathrm{C}$ \\
\hline Average boiling point & $500^{\circ} \mathrm{C}$ \\
\hline Crude oil density in the vessel & $834.2 \mathrm{Kg} / \mathrm{m}^{3}$ \\
\hline Ratio Cp/Hv & $\mathrm{Nil}$ \\
\hline Vessel's liquid height & $0.5 \mathrm{~m}$ \\
\hline Hole's Diameter & $50 \mathrm{~mm}$ \\
\hline Molecular weight & 417 \\
\hline
\end{tabular}

\section{RESUlt AND DISCUSSION}

\begin{tabular}{|c|c|}
\hline Quantity & Value \\
\hline Liquid emission rate, $\mathrm{L}$ & $40.2 \mathrm{Kg} / \mathrm{s}$ \\
\hline Total liquid release $\left(W_{T}\right)$ & $36,180 \mathrm{Kg}$ \\
\hline Flash Fraction $(\mathrm{Fv})($ since OT< NBP) & 0 \\
\hline Total pool size $\left(W_{p}=W_{T}\right)$ & $36,180 \mathrm{Kg}$ \\
\hline Pool area $A_{p}$ & $4337 \mathrm{~m}^{2}$ \\
\hline Airborne quantity due to evaporation $A Q_{p}$ & $335 \mathrm{Kg}$ \\
\hline Total Airborne quantity (AQ $=\mathrm{L})$ & $40.2 \mathrm{Kg}$ \\
\hline Hazard Distance for toxic release, $\mathrm{HD}$ & $5454 \mathrm{~m}$ \\
\hline Hazard Distance (Injury), $H D_{i}$ & $1725 \mathrm{~m}$ \\
\hline Hazard Distance (fatality), $H D_{f}$ & $545 \mathrm{~m}$ \\
\hline Area for toxic injury, $A_{t i}$ & $2337050 \mathrm{~m}^{2}$ \\
\hline Area for toxic fatality, $A_{t f}$ & $233283 \mathrm{~m}^{2}$ \\
\hline
\end{tabular}


Risk Assessment and Consequence Evaluation of Loss of Containment in Petroleum Industry

\begin{tabular}{|c|c|}
\hline \hline Hazard distance for flammable release, $H D_{f l}$ & $186 \mathrm{~m}$ \\
\hline Effective diameter of cloud, $D_{f l}$ & $93 \mathrm{~m}$ \\
\hline Area for flammable release fatality, $A_{f l f}$ & $6793 \mathrm{~m}^{2}$ \\
\hline Basic work population density, $D_{p}$ & $0.003 \mathrm{p} / \mathrm{m}^{2}$ \\
\hline Escape factor for Toxic release, $\mathrm{E}$ & 0.033 \\
\hline Effective population density for toxic release, $D_{p e}$ & 0.0001 \\
\hline Escape factor for flammable release, E & 0.1 \\
\hline Effective population density for flammable release, $D_{p e}$ & 0.0003 \\
\hline Effect of ignition, $P_{i}$ & 0.167 \\
\hline Effective population density adjusted for cloud ignition, $D_{p e i}$ & $5.0\left(10^{-5}\right)$ \\
\hline Number of injuries for toxic release, I & 234 \\
\hline Number of fatalities for toxic release, $\mathrm{F}$ & 23 \\
\hline Number of fatalities for flammable release, F & 0.34 \\
\hline
\end{tabular}

\subsection{Classification of Injuries and Fatalities}

\subsubsection{Classification of injury for toxic release}

For the toxic release, the injuries are classified as severity 5, catastrophic consequences.

\subsubsection{Classification of fatalities for toxic release}

For the toxic release, the fatalities are classified as severity 5 , catastrophic consequences.

\subsubsection{Classification of fatalities for flammable release}

For the flammable release, the fatalities are classified as severity 3 , major consequences.

Therefore, for the entire loss of containment, we use the highest classification which is severity 5, catastrophic consequences.

\subsection{Ranking of Consequences}

The injuries for toxic release are ranked 5.

The fatalities for toxic release are ranked 5.

The fatalities for flammable release are ranked 3.

The highest of the ranking prevails; therefore the rank for the entire loss of containment is 5 .

\section{CONCLUSiON}

Based on the methodology employed in this paper for risk assessment and consequence evaluation;

- Process safety and risk management in the petroleum industry can achieve their goal of seeking authentic measures to prevent, mitigate or checkmate loss of containment.

- Appropriate compensation in line with gravity of damage(s) resulting from any incidents of loss of containment could be ascertained from classified and ranked consequences.

\section{REFERENCES}

[1] http://magazine.sfpe.org/special-hazards/risk-assessment-oil-and-gas-energy-industry

[2] http://www.safetys2s.eu/modules/s2s_wp4/docs/S2S_CHEMICAL_EXPOSURE_INDEX.pdf

[3] http://ratical.com/ratville/IPEIE/Ogoni.pdf

[4] AIChE technical manual, . "Estimating the Airborne Quantity for Liquid Releases", Dow s Chemical Exposure Index Guide AIChE/Dow s, 2010.

[5] http://www.hse.gov.uk/research/misc/vectra300-2017-r02.pdf

[6] http://www3.aiche.org/proceedings/Abstract.aspx?PaperID=177364

[7] Disaster Prevention and Management, Volume 19, Issue 1 (2010-02-15)

[8] Bruce K. Vaughen. "Improving operational discipline to prevent loss of containment incidents", Process Safety Progress, 09/2011

[9] http://www.ukfsc.co.uk/files/SMS\%20Material/ECAST\%20Material\%20Jan\%202009/WP3\%20 -\%20HAZARDS\%20IDENTIFICATION.pdf 
[10] http://www.indsafety.com/editorial/2009/dec_09/techedge_02.html

[11] http://www.eimicrosites.org/heartsandminds/ram.php

[12] http://www.fpemag.com/articles/article.asp?i=316

[13] http://www.adnoc.ae/publications/hse_reports/ADNOC_SUS13_EN_FINAL_Spreads.pdf

[14] http://www.aiche.org/ccps/conferences/ppss.aspx

[15] http://www.cid.csic.es/ampera/images/reports/IPIECA\%20AAOP.pdf

[16] http://www.placng.org/lawsofnigeria/node/343

[17] http://www.insipub.com/rjfh/2009/55-64.pdf

[18] Giwa-Osagie, Osayaba. "Financing options in the oil and gas sector in Nigeria", Journal of Energy \& Natural Resources Law, 2015.

[19] http://www.hse.gov.uk/risk/faq.htm

[20] http://www.ajol.info/index.php/naujilj/article/download/82386/72541accessed

[21] http://www.nosdra.org.ng/noscp1.pdf

[22] http://ijmess.com/volumes/volume-III-2014/issue-II-06-2014/full-2.pdf

[23] http://fr.allafrica.com/stories/200106130090.html

[24] http://www.tradevenvironment.eu/uploads/OCDE_GD_92_81.pdf

[25] http://nosdra.gov.ng/index.php?id=40

[26] http://thenationonlineng.net/bonga-spill-shell-to-pay-3b-to-affected-communities/

[27] Ernest S. GLADNEY. "1987 Compilation of Elemental Concentration Data for USGS BHVO-1, MAG-1, QLO-1, RGM-1, SCo-1, SDC-1, SGR-1 and STM-1", Geostandards and Geoanalytical Research, 10/1988

[28] Brian, M. \& Emonena, S (2013). Causes and Effects of Loss of Containment: (Unpublished).

[29] Dharmavaram, \& S. Klein, J. A. (2010). Preventing Loss of Containment through a Systematic Assessment of Hazards, Consequences, and Risks: Dupont Engineering Research and Technology

[30] Duncan, B. \& Duke G. (2013). Process Safety Management and Operational Discipline for Loss of Containment Prevention: Heisenberg Corporation

[31] John, A., Alderman, P. E. \& William Fink (2007). Risk Assessment in the Oil and Gas Energy Industry: Fire Protection Engineering.

[32] Klein, J. A. \& Vaughen. B. K (2010).Preventing Loss of Containment Incidents - Beyond Mechanical Integrity: Cabot Corporation

[33] Kytömaa, H. K., Myers, T. J., Ibarreta, A. F., Ponchaut, N. (2010). Using Real Time Process Models to Detect Loss of Containment and Mitigate Hazards: Exponent Inc.

[34] Laitifa, K. \& Edeth, E. (2012). Analytic and Probabilistic Prevention of Loss of Containment: Ken's Publishers Uyo, Akwa-Ibom.

[35] Mitchell, P. Peters, K. O. \& Johnson, E. (2013). Process Hazard Analysis for Loss of Containment: Debut Corporation

[36] S. A. Mc Coy (associate), S. J. Wakeman, f. D. Larkin (associate), P. W. H. Chung, A. G. Rushton (member), F. P. Lees (fellow) \& P. M. Heino (1999). Fluid Model and Consequence Evaluation Systems: Trans IChemE, Vol 77, Part B

[37] Vaughen, B. K. \& Klein, J. A. (2010). Improving Operational Discipline to Help Prevent Loss of Containment Incidents: Cabot Corporation

[38] Wells, G. L., Phang, C., Wardman, M. \& Whetton, C. (1992). Incident Scenarios: Their Identification and Evaluation, Trans IChemE, Part B, Proc Safe Env Prot, 70 (B4): 179.

[39] Yo-Essien, L. P. E. (2008). Oil Spills Management in Nigeria: Challenges of Pipeline Vandalism in the Niger Delta Region of Nigeria. National Oil Spill Detection and Response Agency (NOSDRA), Abuja - Nigeria

[40] Gedicks, Al. (2001). Resource Rebels: Native Challenges to Mining and Oil Corporations. Boston: South End Press

[41] "Nigeria: Focus on Ogoni Oil Spill."(2001). Integrated Regional Information Networks. United Nations Office for the Co-ordination of Humanitarian Affairs. 
[http://allafrica.com/stories/printable/200106130090.html]

[http://www.africaonline.com/site/Articles/1,3,3283.jsp]

[www.irinnews.org]

[42] Odu C.T. \& Offodum I. (1986). Oil pollution and the environment. Bulletin of Science Association of Nigeria 3(2): $282-289$.

[43] Hearts and Minds Energy Institute, (n.d). 61 New Cavendish Street London W1G 7AR, UK, 